\title{
Game Theory Analysis: The Stakeholder Behavior in the Rural Collective Property Rights System Reform (RCPRSR)
}

\author{
Ruitao Zhang ${ }^{1}$, Ammar Saad $^{1} \&$ Ying Xia ${ }^{1}$ \\ ${ }^{1}$ Chinese Academy of Agriculture Science, Beijing, China \\ Correspondence: Ying Xia, Chinese Academy of Agriculture Science, Beijing, China. Tel: 1-391-128-6317. \\ E-mail: xiaying@caas.cn
}

Received: September 9, 2019

Accepted: October 22, $2019 \quad$ Online Published: November 15, 2019

doi:10.5539/jas.v11n18p272

URL: https://doi.org/10.5539/jas.v11n18p272

The research is financed by The Agricultural Science and Technology Innovation Program (ASTIP-IAED-2019-03).

\begin{abstract}
The Rural Collective Property Rights System Reform (RCPRSR) is a process of evolution along with the equilibrium point of the game theory. It is also an institutional change involving China's primary economic system and rural basic management system. This paper used the stakeholder theory to determine the main stakeholders in the RCPRSR and then analyzed the behavior mechanism of the main stakeholders through the method of game theory. The results indicate that the main stakeholders are farmers, village organizations, and government. The Nash equilibrium solution is executing and joining respectively village organizations and farmers. Game theory also suggests that the RCPRSR is a gradual and repetitive dynamic process, not the result of one-time rational design. Based on the conclusions of the research, it indicates that should raise the enthusiasm of the village organization. This can increase the income of farmers and flourish the rural economy of China.
\end{abstract}

Keywords: Rural Collective Property Rights System Reform, stakeholders, game theory

\section{Introduction}

The Rural Collective Property Rights System Reform (RCPRSR) is a rural system reform that takes villages (groups or towns) as units and distributes the rights and interests of the collective assets (operational assets, resource assets and public welfare assets) in the form of shares to the members of the collective who meet certain standards. The specific criteria refer to the principle of respecting the history, taking into account reality, procedural norms and public recognition. There are also such factors as household registration relationship, rural land contracting connection and contribution to the collective when determining the members of the collective. Since 2015, China has carried out four batches of experimental policy pilot with the point-to-surface. The first batch only included 29 counties (cities and districts) in 2015. The second batch extends to 100 counties (cities and regions) in 2017. In 2018, the pilot expanded to Jilin, Jiangsu and Shandong provinces, 50 prefectures and 279 counties. There are 12 provinces including Tianjin, 39 prefectures including Yuncheng City of Shanxi Province, 163 counties (cities and districts) including Tuoketuo County of Inner Mongolia to execute the RCPRSR. At present, the RCPRSR involves about 1000 counties. Besides, there are 266 self-developing pilots. The five years since 2015, 238,000 villages have established collective organizations, accounting for $40.7 \%$ of the total number of villages; and more than $15 \%$ of the total number of villagers' groups (about759,000 villagers' groups). RCPRSR is a process of evolution along with the equilibrium point of the game theory. It is also an institutional change involving China's primary economic system and rural basic management system. Recently, because of urbanization, the scale of rural collective assets in China has expanded rapidly. At the end of 2016, the total rural collective assets (excluding land) were 3.1 trillion Chinese Yuan. And the average of the assets' value was about 5.6 million Chinese Yuan for each village; especially the collective properties of suburban villages are even larger than others (Changfu, 2018) (Note 1). Farmers should get the fruits of development, which are accumulated by the farmers' long-term hard work. But the question of the ambiguous property rights and unclear attribution leads to the increasingly prominent internal contradictions. The population flow from the 
rural to the urban made the inconsistencies of collective asset management and income distribution increase (Note 2). So it's essential to analyze the rural collective property rights system reform.

The RCPRSR is a complex and repeated dynamic game theory process caused by the differences between the expectations and actual returns of multiple participants. So this process refers to a lot of stakeholders (Note 3). Hence during the RCPRSR, we need to understand the relationship and interest demands, to realize the best situation of multiple game theory stakeholders. Then we can complete the RCPRSR in China in 2021 as planned.

The RCPRSR is a comprehensive rural reform involving multiple stakeholders, so it is necessary to consider the interests of the state, the village collective, and the members during the RCPRSR. And the foundation of the RCPRSR is to protect the rights and interests of farmers and to reasonably divide the property rights of collective assets among the state, village organization, and member (Xingqing, 2016). With the continuous advancement of the RCPRSR, the interests of the rural areas have gradually become characterized by diversification, grouping, and complexity (Xiong, 2018). How to identify the payoffs for different stakeholders under the completed circumstance? Which method can deal with this?

Game theory is a method of studying strategic situations; it has been widely used and has achieved remarkable results in theoretical and applied research. In the game theory process, the stakeholder pursues the maximization of their benefits and the meager cost, driving the evolution of institutional reform (Hongbo, 2010). The farmland property rights system is the most active institutional arrangement when farmland ownership's preference is consistent with the farmer's choice (Yacheng \& Minjuan, 2008). The balanced ownership structure of the "cooperative system" + "shareholding system" formed by farmers and village organizations can effectively stabilize the relationship among the participants in the RCPRSR (Zhongyuan \& Xueyu, 2018). However, there still may be a dilemma what is the power and capital alliance dividing the rights and the interests of farmers during the game theory (Ling, 2019). After reviewing the literature research, we realized there are few of them used the dynamic game theory method to research the stakeholders in the RCPRSR.

The objectives that we want to solve are: what kind of strategy does each stakeholder choose? Which outcome is the most effective under the conflict conditions of maximizing profit and minimizing costs for stakeholders? Resolving the above issues, we use the dynamic game theory to analyze the behaviors of the stakeholders in the pilot reform stage. To clarify the relationship among the interests of the RCPRSR, explore the optimal strategy combination of participating entities.

This paper first identifies the stakeholders in the RCPRSR. Secondly, 'the dynamic game theory analysis of the RCPRSR' includes three parts: The first part is the underlying assumptions (the bureau's players, rational economic man, the dynamic game theory orders, the behavioral decision space, the perfect information, and the payoff hypothesis). The second part uses game theory to construct a model for top-down reform and down-top reform, respectively. The third part discusses game theory outcomes in different situations. Finally, 'conclusions and recommendations' concludes the Nash equilibrium for the RCPRSR and suggests the next steps for further study.

\section{Identify the Stakeholders in the RCPRSR}

A new characteristic of the RCPRSR is a challenge of the piloting process, which involves a wide range, complicated situations, and multiple participants. This paper emphasizes the character of numerous participants. Hence, depending on interest subjects and stakeholder theory, the stakeholders are individuals, groups, or/and institutions which have a stake in the implementation of the RCPRSR. That is, the individuals, groups, or/and institutions join the RCPRSR which promotes or challenges the reform.

Involving the scientific classification of the stakeholders in the RCPRSR will help to smoothly and effectively promote the RCPRSR. According to the stakeholder classification studies, Frederick (1994) divided the stakeholders into direct stakeholders and indirect stakeholders, based on whether there is a direct market transaction relationship with the company or not. Clarkson (1995) parted the stakeholders to primary and secondary stakeholders, based on how close relationship with the company interests. Mitchell (1997) divided the stakeholders into defined stakeholders, prospective stakeholders, and potential stakeholders from three dimensions: legitimacy, power, and urgency.

According to the above three classifications, and combined with the closeness of the RCPRSR, we divide the stakeholders into main stakeholders, secondary stakeholders, and potential stakeholders. The main stakeholders refer to individuals, groups, or/and institutions that directly intervene in the RCPRSR. They are the government (central and local governments), village organizations (Note 4), and farmers. Secondary stakeholders also refer to individuals, groups, or/and institutions that have an indirect interest relationship with the RCPRSR. They are 
the rural credit cooperatives (rural commercial banks), agriculture-related enterprises, forestry departments, and livestock departments. And the potential stakeholders refer to individuals, groups, or/and institutions that have a possible interest relationship with the RCPRSR. The relevance of the stakeholders with the RCPRSR is unalterable. That is, once the potential stakeholders involved in the RCPRSR; they will transform into the main or secondary stakeholders. The potential stakeholders are teaching and research institutions, news media, domestic and foreign Nongovernmental organizations, etc. (Shuifa \& Tiezhen, 2008).

By adopting the RCPRSR, the way of owning the collective assets changed from joint ownership to co-ownership by shares. This transition makes farmers become the direct beneficiaries of collective assets. The RCPRSR is another qualitative leap in China's rural system. It is also a typical "Pareto improvement" (Note 5) and is of considerable significance to the entire rural areas and even the whole country.

The realization of the RCPRSR returns the power and protects the property rights for the farmers. Farmers are both a profit seeker and a producer of subsistence, but the choice of farmers is chiefly governed by institutional arrangements (Yuhua, 2002b), and homogenized by the living environment. The government is the maker and leader of the RCPRSR and has absolute advantages in resource allocation and political power; it is a powerful promoter for the RCPRSR. The village organizations are also one of the main stakeholders in the RCPRSR. It is also the primary bearer of the risk the RCPRSR.

During the RCPRSR, all stakeholders have the same combination of interests, but there are also differences. They all hope to achieve their optimal goals or maximize benefits through the RCPRSR. In the process of RCPRSR, itis inevitable to bring new contradictions and problems, so it is necessary to find new balance points among the different rights for all stakeholders.

\section{Dynamic Game Theory Analysis of the RCPRSR}

RCPRSR is a significant issue for the government, village organizations, and farmers. For a better understanding of the benefits of stakeholders under different circumstances, this paper uses the dynamic game theory with complete information to analyze the main payoffs of the stakeholders. "Game theory is a science that studies how to make strategic decisions and take strategic actions in a tactic environment" (Hongye, 2004). Before the 1970s, game theory was only used in the field of economics, but now it has been widely used in sociology, psychology, politics, and business, etc. Common game forms are strategic form and extensive form. The extensive game is mainly suitable for dynamic game process analysis. Its outer features are "decision tree" or "game tree" with information adequacy and information inadequacy according to the information completeness of players. This paper mainly studies the dynamic game among participants of different forms of RCPRSR under the condition of sufficient information.

\subsection{Basic Assumptions}

Before conducting a game theory analysis, we usually make some assumptions:

(a) Players: The players are the main stakeholders in the game theory model. They are the government, village organizations, and farmers, who are the decision and strategy makers of the game theory. The government is one of the direct stakeholders involved in the game theory; it is the leader and the principal player in the RCPRSR. The village organizations are the exact executor of the RCPRSR; therefore, it is also a significant beneficiary. While the farmers are one of the direct clients and the primary beneficiaries of the RCPRSR.

(b) "Rational economic man": during the RCPRSR, the government pursues the maximization benefits of economic and social welfare. The village organizations pursuit collective commercial interests and get support from the farmers. While farmers as grassroots groups, the purpose is not to pursue maximum profits, but to satisfy the consumption needs of their families (Yuhua, 2002a).

(c) The dynamic game theory orders: In the early time of the RCPRSR, there were two forms of development: one is a top-down form of mandatory government reform (Where the government selects some of the distinguished villages for applying the RCPRSR), and when this reform success, will spread to the other hamlets. The other one is a down-top rural independent exploring reform. Where the order, of the game theory, first is the village organization independently explores the RCPRSR. Secondly, the farmers should participate in the RCPRSR, and finally, the government approves it.

(d) Strategy: The strategy includes different actions, what the player will act when another player makes a move according to their experience. This study assumes that the government has non-ratification (non-pilot areas) and ratification (pilot areas) two strategies. Village organizations have become pilot and non-pilot tactics. Farmers have two policies of joining the reform and not joining the RCPRSR. 
(f) The perfect information: Assume that the government, village organizations, and farmers understand each other's behavioral strategy and payoff function. And all of them have complete information.

(e) The payoff hypothesis: The payoff represents show many utilities the stakeholders can get when they join the RCPRSR (Tables 1 and 2). Once the players in the game theory take the strategy (adopting RCPRSR), they will get the payoff.

\subsection{Outcome of the Top-Down Reform Model}

In 2015, the government of China launched a pilot of the RCPRSR from top-down. The primary role was to select pilot areas based on specific criteria and give financial support. Therefore, analyzing the top-down reform model where the major stakeholders were village organizations and farmers. $h$ and $i$ represents the payoff of farmers and village organization respective when they both join the reform; $j$ means the payoff of farmers when only farmers join the reform; $\mathrm{k}$ stands for the payoff of village organization when only village organization accept the reform. Assuming that $\mathrm{h}, \mathrm{i}, \mathrm{j}$, and $\mathrm{k}$ are all greater than 0 . Table 1 shows the dynamic game theory process of top-down reform.

Table 1 the game theory model of farmers and village organizations in pilot areas

\begin{tabular}{llll}
\hline & & \multicolumn{2}{c}{ Village organization } \\
\cline { 3 - 4 } & & Accept & Not accepted \\
\hline \multirow{2}{*}{ Farmer } & Join & $\mathrm{h}, \mathrm{i}$ & $\mathrm{j}, 0$ \\
& Not-joined & $0, \mathrm{k}$ & 0,0 \\
\hline
\end{tabular}

In this game theory process, there are four theoretically strategies: (join, accept), (join, not accepted), (not-joined, accept), and (not-joined, not accepted) for farmers and village organizations, respectively. From the maximization utility, there is a profitable strategy for farmers and village organizations, that is, farmers choose to join, and village organizations choose to accept. Therefore, the Nash equilibrium of the game theory model is (join, accept) and the equilibrium payoff is (h, i). Under this condition, farmers and village organizations have coincident preferences, forming a game theory equilibrium point, and getting the most benefits. Recently, the RCPRSR has achieved fruitful results. The scope of the pilot has covered more than 1,000 counties in China (That is more than 130,000 rural collective economic organizations have completed reforms, confirming more than 200 million collective members) (Changfu, 2018). And farmers get the cumulative share has reached 325.1 billion Chinese Yuan from the RCPRSR. The farmers have more real gains of sensibility and happiness in the RCPRSR (Changfu, 2018).

\subsection{The Outcome of the Down-Top Reform Model}

To apply the down-top reform model, we need to estimate the game theory tree. Based on the players' strategies, analyze the outcome to determine the perfect condition for all players.

\subsubsection{The Tree of the Game Theory}

Unlike the top-down reform, in the down-top reform, the government will ratify the legitimacy of the reforms after success. Due to the expansion of the scale of collective assets and the internal contradictions caused by the ambiguity of property rights, often leading to the infringement of farmers' rights occur. Hence, some regions have independently explored RCPRSR. The order of the game theory here is: firstly, the village organization made decisions. In the case of the village organization decided to join the reform, the farmers can take their decision (accepted the reform or not). The last step of the down-top reform, the government will make the final decision by ratifying the reform or not, when the village organization and the farmers both agree to join the reform. The figure below is representing the order and the steps of the down-top reform. 


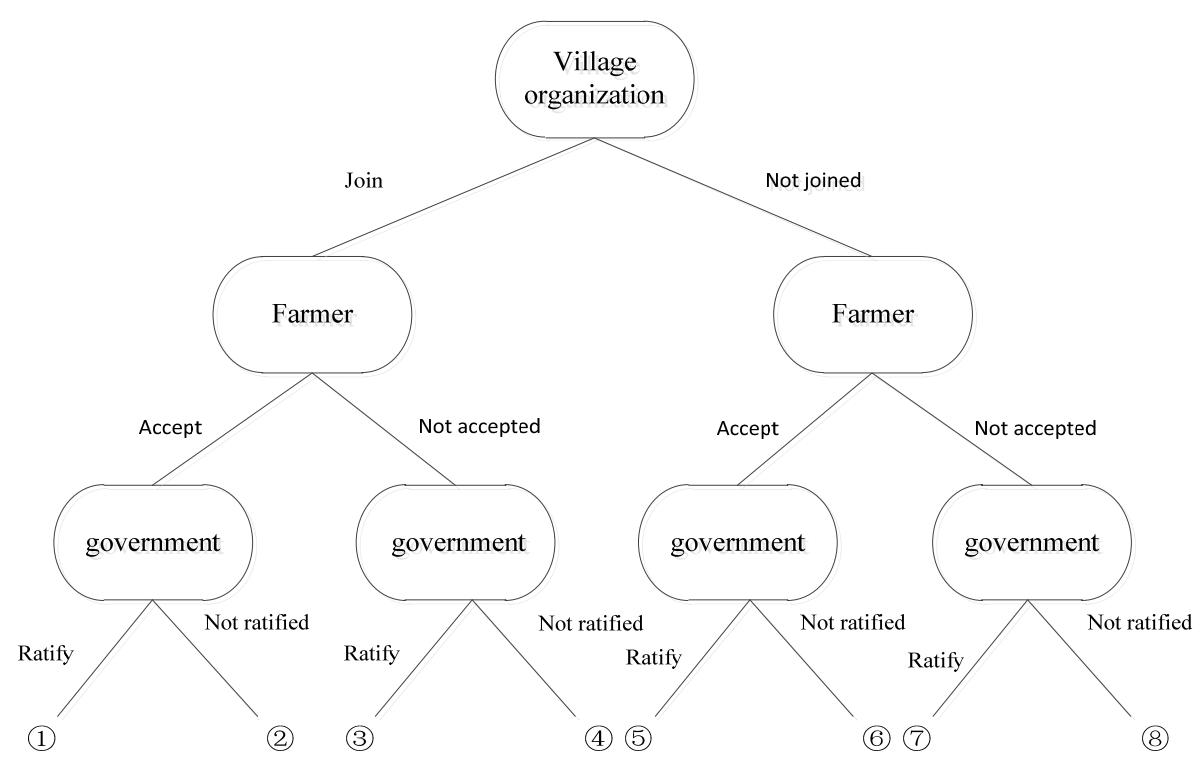

Figure 1. Independently exploring the game theory tree of participants in the reform

\subsubsection{Analyzing the Game Theory Tree Outcome}

During the down-top RCPRSR, the payoffs hypotheses of each player are:

(1) Village organizations': The payoff of the village organizations before independent exploration of the reform is (a), and after joining the reform is (A), and the price is (C). Otherwise, the cost is (0). If the village organizations independent explore reform and achieve excellent results. Meanwhile, the government ratifies. The village organizations will receive the reward $(\mathrm{R})$ when the farmers do not join the village organizations will gain $(0)$.

(2) Farmers': the farmers' payoff is (b) before joining in the reform, and the farmers can get revenue (B) after participating in the reform. If the village organization independently explore the reform and succeed, the farmers who join will gain $(\Delta \mathrm{B})$.

(3) Government's: The primary responsibility of the government is to judge whether village organizations can carry out the reform or not. Before the ratification, the government's revenue is (d), after that; the payoff is (D). Ratifying the process of down-top reform, the government requires to cost (E).

According to the different strategies, we can get the game theory tree for the village organizations, farmers, and government, as shown in Figure 1. Depending on the game theory tree, we can construct the game theory matrix (Table 2). Using the backward induction method to find the subgame theory perfect Nash equilibrium in the dynamic game theory:

The first condition: When " $\mathrm{A}-\mathrm{C}>\mathrm{a}$ " that is, whether the government ratified the reform or not, as long as the village organizations independently explore the reform, it can obtain higher payoff than before. This condition leads to two outcomes:

From the perspective of village organization, the first outcome is the village organizations independently explored reform, and the farmers participated in the reform, and finally, the government ratified the reform. The payoff is (1) $|\mathrm{A}-\mathrm{C}+\mathrm{R} \quad \mathrm{B}+\Delta \mathrm{B} \quad \mathrm{D}-\mathrm{E}|$ to the village organizations, farmers, and government respectively. If so, the village organizations and farmers will get the highest payoff.

From the perspective of the minimum cost of the government, the other outcome is (join, accept, not ratified) to the village organizations, farmers, and government respectively. The payoff is (2) $|A-C \quad B+\Delta B \quad d|$.That is, the village organizations and farmers will receive higher payoff than before the reform, even if the government didn't ratify the reform.

The second condition: When " $\mathrm{A}-\mathrm{C}<\mathrm{a}<\mathrm{A}-\mathrm{C}+\mathrm{R}$ ", there is only one outcome, which the payoff is (1) $|\mathrm{A}-\mathrm{C}+\mathrm{R} \quad \mathrm{B}+\Delta \mathrm{B} \quad \mathrm{D}-\mathrm{E}|$ to the village organizations, farmers, and government respectively. Under the government's ratification, the village organization can independently explore reforms to obtain higher revenue 
than before. The government's confirmation can increase the enthusiasm of the village organization to deepen the reform.

The third condition: When " $\mathrm{a}>\mathrm{A}-\mathrm{C}+\mathrm{R}$ ", in this case, even if the government ratified the reform, the village organization cannot adopt the reform independently, because the village organization will get less payoff than before the reform. Under this situation, the outcome will be (8) $|\mathrm{a} \quad \mathrm{b} \quad \mathrm{d}|$ to the village organizations, farmers, and government respectively. Depending on the "rational economic man hypothesis," the best choice is not joining the reform.

Table 2. The matrix result of players

\begin{tabular}{|c|c|c|c|c|}
\hline \multirow{2}{*}{ No. } & \multicolumn{3}{|c|}{ The state of the game theory } & \multirow{2}{*}{ Game Theory Matrix } \\
\hline & Village Organization & Farmer & Government & \\
\hline (1) & execute & Join & Recognize & $|\mathrm{A}-\mathrm{C}+\mathrm{R} \quad \mathrm{B}+\Delta \mathrm{B} \quad \mathrm{D}-\mathrm{E}|$ \\
\hline (2) & execute & Join & Not recognized & $|\mathrm{A}-\mathrm{C} \quad \mathrm{B}+\Delta \mathrm{B} \quad \mathrm{d}|$ \\
\hline (3) & execute & Not joined & Recognize & $\left|\begin{array}{lll}0 & \mathrm{~b} & \mathrm{D}-\mathrm{E}\end{array}\right|$ \\
\hline (4) & execute & Not joined & Not recognized & $\left|\begin{array}{lll}0 & \mathrm{~b} & \mathrm{~d}\end{array}\right|$ \\
\hline (5) & Not executed & Join & Recognize & $\left|\begin{array}{lll}\mathrm{a} & \mathrm{B} & \mathrm{D}-\mathrm{E}\end{array}\right|$ \\
\hline (6) & Not executed & Join & Not recognized & $\left|\begin{array}{lll}\mathrm{a} & \mathrm{B} & \mathrm{d}\end{array}\right|$ \\
\hline (7) & Not executed & Not joined & Recognize & $\left|\begin{array}{lll}a & \mathrm{~b} & \mathrm{D}-\mathrm{E}\end{array}\right|$ \\
\hline (8) & Not executed & Not joined & Not recognized & $\left|\begin{array}{lll}\mid a & b & d\end{array}\right|$ \\
\hline
\end{tabular}

\subsection{Discuss the Game Theory Outcomes}

The RCPRSR is an institutional change to China's rural system. Institutional changes are equivalent to the game theory transfer from one equilibrium to another. The result is not only related to the overall qualitative change in the strategy (rules of action choice); it's also associated with the changes in the participants' common beliefs. The RCPRSR changed the rural system, from the double-layer management system, which is based on family contract management, to the cooperative stock system with clear property rights. This change also makes the relationship between the cadres and the farmers more harmonious.

In the case of the top-down reform: the optimal strategy of the dynamic game theory for village organization and farmer is (join, accept) respectively, and get the payoff is (h, i) $(\mathrm{h}>0 ; \mathrm{i}>0)$. In this outcome, the stakeholders actively join the RCPRSR, the village organizations can complete the task with high quality and develop the collective economy, and the farmers can increase their revenue.

In the case of the down-top reform: the first condition is feasible. That is, regardless of the government ratified or not, the payoff is higher than before the reform, which is the prerequisite for inspiring village organizations to explore the RCPRSR independently. The RCPRSR is to possess collective assets (including operating assets, resource assets, and public welfare assets) and collective revenue by shares to collective members. The down-top reform is helping to increase and develop the collective economy of the village organizations and farmers' revenue.

According to the second condition, it is clear that the payoff is lower than before the RCPRSR. However, if the government ratified the reform, the village organizations will get higher payoff and have the motivation to join the reform. The government's ratification can increase the enthusiasm of the village organizations to adopt the RCPRSR. And it also can improve the farmers' living quality, thereby enhancing farmers' sense of gain.

According to the third condition, the outcome is not economically feasible. Even if the government ratified the reform, the village organizations would get fewer payoffs than before joining the reform. So maintaining the original state is the best choice. The reasons may be: the farmers are entirely unconcern for the RCPRSR, and they think the RCPRSR is an event of wasting power and money. Secondly, the village organizations have little collective assets, and the income gap between local urban and rural residents is not significant. So the RCPRSR isn't necessary.

Briefly, whether it is top-down or down-top reform, the best strategy for village organizations and farmers is (join, accept) respectively. The government plays an incentive role to the RCPRSR, the pilot designation, and ratification both encourage the village organizations and farmers to join the RCPRSR. 


\section{Conclusions and Recommendations}

Through the above analysis, we can get that RCPRSR is a systematic rural system reform. This change mainly adjusts the interests of the government, village organizations, and farmers. It is also the initiative choice which is a multiple complex game theory of numerous stakeholders in the rural areas. Recently, due to RCPRSR, the average revenue of the rural collective organizations has reached 462.7 billion Chinese Yuan, and close to 30\% of the villages with annual operating revenue in China are exceeding 50,000 Chinese Yuan (Zhao, 2019).

\subsection{Conclusions}

There are many stakeholders (government, village organizations, farmers, rural commercial banks, agriculture-related enterprises, forestry departments, teaching and research institutions, news media, domestic and foreign Nongovernmental organizations, etc.). The main stakeholders are government, village organizations, and farmers in the RCPRSR.

Regardless of how to execute the RCPRSR, the Nash equilibrium solution is (join, accept) for village organizations and farmers, respectively. As long as the collective economy can develop, and farmers can increase the revenue, the government should encourage the stakeholders to adopt the reform.

The RCPRSR is a gradual and repetitive dynamic game theory process, not the result of one-time rational design.

\subsection{Recommendations}

Based on the conclusions of the research, we put forward some recommendations:

(1) The RCPRSR is a comprehensive rural reform involving multiple stakeholders. We should keep balance among the stakeholders to guarantee the RCPRSR to succeed.

(2)We should raise the enthusiasm of the village organization. It helps increase the income of farmers and flourish the rural economy of China.

\section{References}

Changfu, H. (2018). Han Changfu emphasized the continuous deepening of rural collective property rights system reform and laid a solid institutional foundation for rural revitalization in the national rural collective property rights reform pilot promotion meeting. Ministry of Agriculture and Rural Affairs of the People's Republic of China. Retrieved from http://www.moa.gov.cn/xw/zwdt/201811/t20181116 6163171.htm

Clarkson,M. E. (1995). A Stakeholder Frame Work for Analyzing and Evaluating Corporate Social Performance. Academy of Mangement Review, 20(1), 92-117. https://doi.org/10.5465/amr.1995.9503271994

Frederick,W. C. (1994). Form $\mathrm{CRS}_{1}$ to CRS2 :The mataring of bussiness-and-society Thought. Bussiness-and-Society, 33(2), 150-163. https://doi.org/10.1177/000765039403300202

Hongbo, L. (2010). Analysis of Dynamic Game Analysis of Land Acquisition System Reform. China Land Science, 24(10), 25-29.

Hongye, G. (2004). Western Economics, Microscopic Part (pp. 288-298). Renmin University of China Press.

Ling, C. (2019). The Interest Game and Dilemma Analysis of Large-scale Circulation of Agricultural Land. Journal of Party School of Ningbo Municipal Committee, 41(1), 120-128.

Mitchell, A., \& Wood, D. J. (1997). Toward a theory of stakeholder identification and salience: defining the principle of who and what really counts. academy of management review. Academy of Management Review, 22(4), 853-886. https://doi.org/10.5465/amr.1997.9711022105

Shuifa, K., \& Tiezhen, Z. (2008). A Dynamic Game Analysis of Stakeholder Behavior in the Project of Returning Farmland to Forests. Forestry Economics, 1, 47-50.

Xingqing, Y. (2016). The method of reforming rural collective property rights system determines success or failure. China Economic Times (pp. 1-3).

Xiong, W. (2018). From "Seeing Things" to "Seeing People": A Probe into the Interest Coordination of Rural Collective Economic Organizations. Journal of Sichuan Normal University (Social Science Edition), 45(1), 89-97.

Yacheng, L., \& Minjuan, Z. (2008). The Game Research between Farmers and Village Organizations in the Changes of China's Agricultural Land Property Right System. Journal of Anhui Agricultural Sciences, 25, 11099-11101. 
Yuhua, G. (2002a). "Daoyi Economy" or "Rational Small Farmers" Rereading the Classics of Farmer Studies. Reading, 5, 104-110.

Yuhua, G. (2002b). "Weapons of the Weak" and "Hidden Texts"-A Study of the Underlying Perspective of Farmer Rebellion. Reading, 7, 11-18.

Zhao, K. (2019). Ministry of Agriculture and Rural Areas: Deepening the Reform of Rural Collective Property Rights System. Retrieved from http://news.sina.com.cn/c/2019-03-29/doc-ihsxncvh6510342.shtml

Zhongyuan, X., \& Xueyu, C. (2018). The Legal Personnel of Rural Collective Economic Organization under the Vision of "Three Powers Separation". Contemporary Jurisprudence, 32(1), 83-92.

\section{Notes}

Note 1 . There are about $49.77 \%$ (the total numbers of farmers is 576.61 million) migrant workers worked in the city in 2017 (Han, 2018).

Note 2 . The village includes city villages, suburban villages, and urban villages in China.

Note 3. There are main stakeholders, secondary stakeholders, and potential stakeholders.

Note 4 . The village organization includes village party branches, village committees, and collective economic organizations three parts in China.

Note 5. After the rural collective property system reform, no farmer's rights hurt; on the contrary, this reform even protects their rights. This phenomenon is consistent with Pareto improvement.

\section{Copyrights}

Copyright for this article is retained by the author(s), with first publication rights granted to the journal.

This is an open-access article distributed under the terms and conditions of the Creative Commons Attribution license (http://creativecommons.org/licenses/by/4.0/). 